\title{
Evidências de validade da Escala Informatizada de Atitudes frente à Estatística - eSASPortuguês: um estudo correlacional
}

\author{
Claudette Maria Medeiros Vendramini' - Universidade São Francisco, Itatiba, Brasil \\ Juliana Maximila de Paula Bueno - Universidade São Francisco, Itatiba, Brasil \\ Evelyn Christina Peres Barrelin - Universidade São Francisco, Itatiba, Brasil
}

\begin{abstract}
Resumo
Esta pesquisa objetivou investigar as evidências de validade da versão informatizada de uma escala de atitudes frente à Estatística. Participaram deste estudo 35 estudantes de psicologia que cursavam a disciplina de estatística no primeiro semestre de 2010 de uma universidade particular do interior do estado de São Paulo, todos do período noturno, 82,9\% do gênero feminino, com idades variando entre 17 e 56 anos $(M=23 ; D P=9,3)$. Os estudantes responderam à escala de atitudes SASportuguês, composta de 33 itens, do tipo Likert de cinco pontos, nas versões informatizada e lápis-papel. Os alunos foram distribuídos aleatoriamente em dois grupos; o primeiro respondeu à versão lápis-papel e em seguida à versão informatizada, e o outro respondeu na ordem inversa. Os resultados indicaram uma correlação linear positiva significativa entre as duas versões da escala revelando validade da versão eletrônica. A versão lápis-papel da escala já apresentava evidências de validade comprovada em pesquisas anteriores.

Palavras-chave: Psicometria, Ensino superior, Avaliação informatizada.
\end{abstract}

Validity evidences of the Electronic Scale of Attitudes towards Statistics - eSASportuguês: a correlational study

\begin{abstract}
This research aimed to investigate the validity evidences of an electronic version of an attitude scale towards statistics. A total of 35 psychology students taking Statistics classes during the first half of 2010 at a private university of São Paulo state participated in this study. All students studied in the night period, $82.9 \%$ were female, aged 17 to $56(M=23,0$; $S D=9,3)$. The students answered the attitude scale SAS Portuguess that consisted of 33 Likert items with five points, in both electronic and pencil-paper versions. The students were distributed randomly in two groups; the first answered the pencilpaper version followed by the electronic version, and the other answered in the inverted order. The results indicated a significant positive linear correlation between the two scale versions confirming the electronic version's validity evidences. The pencil-paper version scale had already presented validity evidences confirmed in previous studies.

Keywords: Psychometrics, High education, Electronic assessment.
\end{abstract}

O avanço tecnológico tem criado condições para um crescente e sistemático aumento na utilização de computadores e derivados da informática na vida e no trabalho das pessoas. Coerente com essa prerrogativa verifica-se, na área da testagem psicológica, a transformação de testes e escalas psicométricas do formato lápis-papel para a versão eletrônica e/ou informatizada (Prado, 2005). Com o avanço tecnológico também tem sido possível avaliar construtos mais complexos por meio da informatização de testes, tais como a psicomotricidade, os interesses, as atitudes, as aptidões e a inteligência (Andriola, 2003; Olea, Ponsoda \& Prietro, 1999).

Os instrumentos só podem ser chamados de informatizados, de acordo com Adánez (1999), quando sua organização e aplicação são feitas por computador ou via internet. Pasquali (2010) acrescenta que os testes informatizados devem ter como suporte $\mathrm{O}$ computador, considerando todas as fases de execução da testagem, desde a apresentação do instrumento, instruções, exposições de exemplos, apresentação dos

${ }^{1}$ Endereço para correspondência:

Rua Herculano Pupo Nogueira, 309 - Vila Belém - 13256-300 Itatiba-SP

E-mail: claudette.vendramini@saofrancisco.edu.br;

cvendramini@uol.com.br itens, realização do registro de dados, respostas por meio do teclado, mouse, microfone ou tela sensível ao toque (touchscreen), codificação numérica de respostas, armazenamento de dados automáticos, correção do teste e emissão de relatórios. Esse autor ressalta ainda que instrumentos que são respondidos na forma lápispapel e corrigidos por leitores ópticos não devem ser considerados instrumentos informatizados.

Pela maior incidência da informática na construção, aplicação e uso de testes, a American Psychological Association - APA (1986, citado por Olea e colaboradores, 1999) elaborou diretrizes específicas que asseguram a regularização dos mesmos, para que contemplem os requisitos exigidos a um instrumento científico de medida. São sete citações consideradas relevantes na utilização dos testes, as quais se referem à garantia de padronização do procedimento de aplicação, a uma maior limitação das interpretações, à garantia das condições relacionadas aos fatores humanos, assegurando qualidade melhor ou semelhante aos testes convencionais, ao estabelecimento de propriedades psicométricas com fundamentos que justifiquem a interpretação das pontuações da versão informatizada, à consistência da classificação, à validade das interpretações 
informatizadas e aos aspectos referentes à revisão por especialistas da área.

A International Test Comission (ITC) também estabelece diretrizes para a adequação da avaliação informatizada, em que os testes devem ser acessíveis on-line, off-line, realizada por meio de CD-Rom e/ou por download viabilizando uma avaliação plena. Este órgão estabelece critérios para os diferentes modos de aplicação, que podem ser: aplicação aberta, onde não há supervisão humana durante a realização e o acesso é livre; aplicação controlada, que não conta com a supervisão humana, mas necessita de senha e código de acesso para responder ao instrumento; aplicação supervisionada, como o próprio nome já diz conta com supervisão humana e requer registro de segurança (senhas e códigos de acesso), garantindo a participação completa do indivíduo; e a aplicação administrada, com elevado controle e supervisão na execução do teste, desde o acesso de segurança, qualificação dos aplicadores e especificações técnicas de equipamento (Joly e colaboradores, 2005).

Segundo Joly, Martins, Abreu, Souza e Cozza (2004), a utilização de instrumentos na versão informatizada é importante e tem sido frequente nos Estados Unidos e Europa; e em países como Argentina, Portugal e Espanha (Andriola, 2003). No Brasil, o surgimento de testes informatizados inicia-se com um teste para avaliar as Condições e Hábitos de Estudo (CHE) e a Bateria de testes destinada à área de Orientação Vocacional (Andriola, 2003). Em nosso país, ainda é limitada a produção experimental de instrumentos nacionais informatizados, que é maior do que sua comercialização e, portanto, não disponível para o uso profissional (Prado, 2005).

O aumento da procura pelo desenvolvimento da informática para a testagem psicológica deve-se às contribuições que essa prática pode proporcionar, tendo vantagens relacionadas às condições de aplicação e ao processamento das respostas e sua interpretação, tais como: redução do tempo de aplicação, menor custo, maior confiabilidade nas respostas aos itens, maior interação com o examinado, permitindo $\mathrm{O}$ feedback; possibilidade de criação de um banco de questões, controle de participação do indivíduo, riqueza de material para estimulação, padronização, correção, e armazenamento de dados automaticamente (Cory, 1977 citado por Andriola, 2003; Kingsburry \& Houser, 1999 citado por Joly e colaboradores, 2005; Noronha, Santos \& Sisto, 2006; Olea e colaboradores, 1999; Paquali, 2010).

Entretanto, é preciso considerar alguns aspectos importantes que podem causar problemas e desvantagens na testagem informatizada, como, por exemplo: a impossibilidade de acesso ao uso de computadores ou internet; falta de familiaridade com o computador e subsequente alteração das atitudes em relação ao mesmo; insuficiência da qualidade técnica do instrumento, mesmo quando já validado; problemas de interpretação, por parte do participante, sem que haja a possibilidade de auxílio do aplicador (Kumar, 1996; Wall, 2000, citados por Noronha e colaboradores, 2003). Variáveis como idade, gênero e lugar onde mora (rural ou urbano) podem influenciar na familiaridade do participante com relação ao computador e também influenciar em suas atitudes (Olea e colaboradores, 1999). Igualmente, Andriola (2003) salienta a possibilidade de que variáveis implícitas ao procedimento, como o formato do software, a familiaridade com relação ao programa, as atitudes frente ao computador, possam influenciar o desempenho individual do participante.

Considerando que todo instrumento deve possuir propriedades psicométricas válidas, Joly e colaboradores (2005) realizaram uma pesquisa com o objetivo de construir o primeiro Sistema de Avaliação de Testes Informatizados (SAPI) para avaliar e caracterizar instrumentos de avaliação psicológica informatizados. Esse instrumento é composto por 42 itens, sendo 21 perguntas abertas e as demais perguntas fechadas, respondidas por juízes considerados especialistas das áreas de avaliação psicológica e tecnologia da informação e comunicação. Dessa forma os autores disponibilizam um sistema de avaliação de instrumentos, já construídos ou em construção no Brasil, válido e fidedigno para ser utilizado por profissionais que se interessam em avaliar os instrumentos informatizados a serem utilizados em suas pesquisas.

Poucos são os estudos com testes informatizados encontrados na literatura. Entre eles cita-se a pesquisa experimental realizada por Andriola (2003), que objetivou verificar se há diferenças significativas de desempenho de alunos do ensino médio, ao responderem um Teste de Raciocínio Numérico $(\mathrm{RN})$, entre a versão lápis-papel e a versão informatizada. O autor coletou uma amostra de 143 alunos do ensino médio de uma escola pública de Fortaleza, entre eles 71 homens e 72 mulheres, com idade média de 17,28 anos $(D P=2,19)$ distribuída entre dois grupos: grupo controle $(\mathrm{GC})$, que respondeu à versão lápis-papel, e grupo experimental (GE), que respondeu ao teste no formato informatizado. Os resultados mostraram que o desempenho dos alunos não variou significativamente, em ambas as versões, pelo Teste da Análise de Variância (ANOVA), sendo $(F[1,141]=1,183 ; p>0,050)$; porém, em relação à variável idade, verificou-se uma diferença significativa de desempenho $(F[2,141]=5,684 ; p<0,050)$, tendo sido 
observada uma tendência de decréscimo no desempenho das respostas à medida que a faixa etária aumentava, sugerindo que pessoas "a partir dos 17 anos apresentam relativa estabilidade cognitiva" (p. 110). Também foram observadas pelo autor diferenças significativas de desempenho segundo o gênero $(\mathrm{F}[1,141]=1,873 ; p<0,050)$, tendo sido os homens superiores no raciocínio numérico em relação às mulheres.

Outro estudo que envolve a informatização de testes foi realizado por Olea e Hontangas (1999), como citado por Joly e colaboradores (2005). Nesse estudo, os autores compararam testes lápis-papel e informatizado e concluíram que os testados tendem a ser mais honestos e sinceros na versão informatizada. No Brasil, o número de artigos relacionados a características psicométricas e instrumentos informatizados é reduzido, o que gera a falta de informação, desconfiança e descrédito em relação a esse procedimento de avaliação (Joly e colaboradores, 2005). Nesse sentido, o presente estudo reafirma a importância e a possibilidade de que instrumentos antes impressos venham a ser informatizados e que a construção de novos instrumentos informatizados possa ser também realizada, a fim de disponibilizar e aumentar a variabilidade de testes disponíveis no mercado para uso profissional, entendendo que o uso de softwares para a testagem psicológica está inteiramente associado à obtenção de dados estatísticos e rapidez de correção, otimizando o tempo de trabalho do psicólogo (Muñiz \& Hambleton, 1999, como citado por Joly \& colaboradores 2005).

Assim, esta pesquisa teve como objetivo investigar as propriedades psicométricas de uma escala de atitudes em relação à estatística na versão informatizada. $\mathrm{O}$ interesse pela adaptação do formato lápis-papel para o informatizado deve-se à necessidade de disponibilizar instrumentos válidos e fidedignos aos professores e pesquisadores em educação estatística, com menor custo em sua aplicação e com a geração mais rápida de relatórios finais que possam auxiliá-los em suas tomadas de decisões e adoção de estratégias de ensino que melhorem a qualidade da aprendizagem dos estudantes em estatística. De acordo com Gal e Ginsburg (1994), professores que ministram a disciplina de estatística devem atentar aos aspectos afetivos do processo de ensino-aprendizagem, como, por exemplo, ansiedades, frustrações e atitudes, com o objetivo de propor estratégias que reduzam ou eliminem os aspectos negativos desse processo e prepararem o estudante para não sentir medo de utilizar métodos estatísticos em suas análises de dados de pesquisa (Vendramini, 2006). Nas palavras de Silva, Brito, Cazorla e Vendramini (2002), é importante que os professores lidem com os aspectos afetivos associados à estatística verificando logo no início de um curso, ou de uma disciplina, qual é a prontidão/atitude do aluno para realizá-la. Além disso, as autoras recomendam que essas atitudes sejam também verificadas no final do curso, ou disciplina, para saber como o estudante se sente após realizá-la.

Uma das pesquisas realizadas com esse objetivo foi desenvolvida por Silva, Vendramini e Dias (2007), que avaliaram as atitudes de estudantes de psicologia em relação à estatística em duas universidades da região sudeste, com uma amostra de 361 participantes, com idades de 18 a 65 anos, sendo $81 \%$ mulheres e $53 \%$ participantes do período noturno. As autoras obtiveram como resultado que as atitudes são ligeiramente mais negativas do que positivas em relação à estatística e que há diferenças significativas entre as universidades, turno, série e reprovações na disciplina, bem como a existência de correlações positivas e significativas entre atitude, desempenho acadêmico e autopercepção de desempenho do estudante.

Ter atitudes mais positivas facilita o processo da aprendizagem, melhorando o desempenho do aluno, por isso se faz importante conhecer as atitudes dos mesmos (Vendramini \& Brito, 2001). Nesse sentido, o estudo dos processos afetivos e cognitivos torna-se de grande relevância no âmbito do ensino de estatística e de outras disciplinas, pois atitudes negativas dos estudantes com relação a uma dada matéria/disciplina podem comprometer o seu aprendizado e o uso adequado dessa ferramenta de análise de dados na vida profissional futura.

A estatística permite a organização e interpretação de grande volume de dados e é importante na formação científica e técnica dos profissionais, por isso, essa disciplina faz parte da maioria das grades curriculares dos cursos de graduação e pós-graduação (Vendramini, 2010). Docentes que ministram a disciplina de estatística geralmente focam sua atenção na transmissão do conhecimento ao aluno, entendendo que este pode "deixar de apreender" por déficits cognitivos, porém Gal e Ginsburg (1994) assinalam que os aspectos afetivos, as atitudes negativas e crenças do aluno com relação à estatística são fatores que dificultam a aprendizagem do estudante, bem como a aplicação dos conceitos que apreenderam em aula.

O estudo das atitudes se faz necessário, dada a possibilidade de prever e controlar (da melhor maneira possível) o comportamento das pessoas ante um determinado objeto social. Nesse sentido, ressaltase a utilização de instrumentos confiáveis, válidos e adaptados à população-alvo e para medir atitudes 
como, por exemplo, as escalas de atitudes (Moriya, Gir \& Hayashida, 1994).

Pesquisas referentes a atitudes com relação à estatística começaram a se desenvolver, nos Estados Unidos, no início da década de 80 do século passado. Tempo relativamente recente quando comparado aos estudos sobre a educação matemática, por exemplo. Em um estudo de levantamento, Carmona (2004) identificou 112 trabalhos de atitudes com relação à estatística entre artigos, teses e trabalhos apresentados em congresso. Nesses trabalhos, a mensuração de atitudes é frequentemente realizada por escalas do tipo Likert, que em sua maioria são compostas por subescalas que apresentam mais de 20 itens com 5 a 7 opções de respostas.

A utilização de instrumentos informatizados para avaliar atitudes em relação à estatística é ainda mais recente e tem motivado pesquisadores a realizarem pesquisas que utilizem esse tipo de instrumento. Assim, o objetivo do presente estudo é investigar as evidências de validade da escala informatizada de atitudes em relação à estatística eSAS Português, por meio de uma análise correlacional entre as versões lápis-papel e eletrônica da escala SAS de atitudes ante a estatística.

\section{Método}

\section{Participantes}

Participaram desta pesquisa 35 universitários do curso de psicologia, de uma universidade particular do interior do estado de São Paulo, que cursavam a disciplina estatística no primeiro semestre de 2010, todos do período noturno, sendo $17,1 \%(N=6)$ do gênero masculino e $82,9 \%(N=29)$ do gênero feminino, com idades variando de 17 a 56 anos $(M=23,0$; $D P=9,3)$.

Dos participantes, 26 responderam às duas versões do instrumento, dos quais 2 universitários responderam apenas à versão informatizada da escala e 7 participantes responderam somente à versão lápispapel. Isso se deve à ausência desses alunos em um dos dias de aplicação dos instrumentos.

\section{Instrumentos}

Os estudantes responderam a dois instrumentos de pesquisa: o Questionário de Identificação, composto por itens de caracterização do universitário; e a versão em português da escala Statistics Attitudes Survey - SAS. A escala original em inglês foi construída por Robert e Bildebark (1980), traduzida e adaptada para o português por Vendramini, Kataoka, Silva e Cazorla (2009, citado por Vendramini, 2010), tendo passado por uma tradução juramentada do inglês para o português e em seguida por uma análise de conteúdo de quatro juízes especialistas em educação estatística. A escala SAS Português, assim como a versão original, é composta de 33 itens do tipo Likert de 5 pontos (1 para discordo fortemente, 2 para discordo, 3 para neutro, 4 para concordo e 5 para concordo fortemente). O objetivo da escala é avaliar a competência em lidar com problemas estatísticos e cálculos, a competência e atitudes para lidar com tarefas matemáticas, o interesse em aprender estatística, crenças sobre a utilidade da estatística e as expectativas quanto à importância da estatística para as suas carreiras. A versão eletrônica eSAS Português foi elaborada por Vendramini e Bueno (2010) preservando as mesmas informações e características da versão lápispapel.

Robert e Bildeback (1980) aplicaram o SAS e três amostras $(\mathrm{N}=92, \mathrm{~N}=81, \mathrm{~N}=65)$, e registraram índices de alfa de Cronbach variando de 0,93 a 0,95. Assim, os autores constataram altas correlações entre os escores do SAS, bem como com o desempenho em estatística. Eles concluem que tal escala, por ser homogênea, pode predizer muito bem o desempenho em estatística, auxiliando, inclusive, na detecção de alunos com medo crônico no início de uma disciplina de estatística.

Informações sobre a validade da escala original, em inglês, foram apresentadas na pesquisa de Roberts e Saxe (1982), que aplicaram esse instrumento em 132 estudantes de um curso introdutório de estatística básica em duas etapas distintas (pré-teste e pós-teste) do período em que os alunos cursavam tal disciplina na Universidade de Pensylvannia, EUA. O estudo analisou as variáveis cognitivas e não-cognitivas, que se apresentaram significativamente relacionadas com a escala SAS e revelaram que todos os itens da escala apresentam cargas fatoriais altas em um único fator geral.

Em estudo realizado por um grupo de pesquisadores de educação estatística de instituições de ensino superior de diferentes estados brasileiros (Vendramini, 2010) com 2.074 alunos de graduação matriculados em uma disciplina de estatística durante o ano letivo de 2009, foi verificado que a escala SAS está correlacionada com outra escala que avalia as atitudes ante a estatística, a escala Survey of Attitudes Toward Statistics $(\mathrm{r}=0,730)$, revelando sua validade.

\section{Procedimento}

$\mathrm{O}$ projeto de pesquisa em questão foi primeiramente encaminhado ao Comitê de Ética e Pesquisa da Universidade São Francisco (USF) e, após aprovação, executado. Os alunos foram aleatoriamente distribuídos, por meio de sorteio semirrandômico, em 
dois grupos: o primeiro respondeu aos instrumentos na ordem versão lápis-papel e informatizada, enquanto o outro respondeu os instrumentos em ordem inversa. Esse procedimento permitiu verificar o efeito da ordem de apresentação dos instrumentos nos resultados de pesquisa. Os participantes foram solicitados a ler o Termo de Consentimento Livre e Esclarecido (TCLE) disponibilizado para o participante na versão impressa, duas vias, e informatizada, que ficou gravada no ambiente virtual da universidade, podendo ser impressa pelo participante quando ele assim o desejar. Após assinarem o TCLE, os participantes responderam aos instrumentos de pesquisa em dois dias, com um intervalo de 15 dias entre as aplicações dos instrumentos nas duas versões. Em ambas as aplicações houve o apoio de um auxiliar de pesquisa. Os alunos foram orientados a realizar uma leitura atenciosa das instruções e das afirmações que compunham o instrumento, sem a possibilidade de auxílio do pesquisador.

\section{Resultados e Discussão}

O escore total obtido pelos sujeitos na escala eSAS português podia variar de 33 a 165 pontos, com ponto médio igual a 82 pontos; portanto, pontuações acima desse ponto indicam atitudes mais positivas que negativas em relação à estatística e pontuações abaixo dele indicam atitudes mais negativas que positivas. Os resultados desta pesquisa indicaram que os estudantes apresentam atitudes mais positivas que negativas, como mostra a tabela a seguir.

Tabela 1. Estatísticas descritivas dos escores totais em ambas as versões da escala SAS $_{\text {português }}$

\begin{tabular}{lccccc}
\hline Versão da escala & $\mathrm{N}$ & $\begin{array}{c}\text { Escore } \\
\text { mínimo }\end{array}$ & $\begin{array}{c}\text { Escore } \\
\text { máximo }\end{array}$ & Média & Desvio padrão \\
\hline Lápis-papel & 28 & 65 & 121 & 94,71 & 14,010 \\
Informatizada & 33 & 60 & 119 & 93,30 & 15,781 \\
\hline
\end{tabular}

Além disso, verificou-se que as médias das pontuações de atitudes em ambas as versões foram similares independentemente da ordem de aplicação do instrumento, sugerindo a inexistência de um efeito de sequência. As atitudes dos participantes não variaram de modo significativo no período entre as aplicações dos instrumentos, que considerou um intervalo de 15 dias entre elas. Ao efetuar uma análise correlacional entre o escore total da versão lápis-papel e o escore total da versão informatizada, verificou-se que existe uma relação linear positiva e altamente significativa entre essas variáveis $(r=0,749 ; p<0,001)$. Esses valores indicam que os participantes que possuem atitudes mais positivas na versão lápis-papel tendem a ter atitudes mais positivas também na versão informatizada, como pode ser observado na Figura 1.

A informatização dos testes gerou uma nova problemática, a equivalência dos meios de avaliação e os aspectos característicos da avaliação informatizada. É preciso ser feita uma análise da equivalência das pontuações das versões informatizada e lápis-papel, devendo estas sustentar duas condições básicas, primeiramente verificar se a ordem das pontuações dos sujeitos é aproximada em ambas as versões e averiguar se as médias, variâncias e forma de distribuições das pontuações são aproximadamente iguais (Pasquali, 2010). Nesse sentido, a análise de correlação deste estudo, apresentada na Tabela 2 , mostra que as versões lápis-papel e informatizada estão fortemente correlacionadas para ambos os grupos de aplicação do instrumento.

As médias dos escores totais por ordem de aplicação foram próximas entre o período de aplicação (exemplo, informatizado-informatizado) e entre as versões, sendo estatisticamente significativas quando aplicadas na ordem informatizado/lápis-papel $([t[26]=0,379 ; p=0,710)$ e com alta correlação na ordem lápis-papel/informatizado $(r=0,925)$, em comparação com o grupo informatizado/lápis-papel $(\mathrm{r}=0,711)$. Ressalta-se que, em nenhum dos casos, a diferença entre as duas versões foi significativa.

Também no estudo realizado por Andriola (2003), os resultados apontaram não haver diferenças significativas quanto ao formato do instrumento, seja lápis-papel ou informatizado, o que corrobora os resultados desta pesquisa, visto que as análises mostram que as atitudes dos estudantes não variaram pela forma de aplicação dos instrumentos. Isso pode sugerir que os participantes não encontraram dificuldades expressivas no manuseio do computador, que, segundo Joly e Martins (2005, p. 105), "As habilidades relacionadas ao uso de tecnologia delineiam um novo modelo para a escola, que deve formar os cidadãos contemporâneos à sociedade moderna", além do computador e da internet estabelecerem vínculos entre os conteúdos acadêmicos e de aprendizagem com a realidade cotidiana. Como ressalta Joly (2004), o desenvolvimento da sociedade tem exigido das pessoas 
padrões de comportamentos adaptados às ferramentas informatizadas, que implica em aquisição de conhecimento e habilidade necessária, desde cedo, para operar um computador em qualquer situação funcional do cotidiano (alfabetização tecnológica) e também que possa contribuir para o ensino.

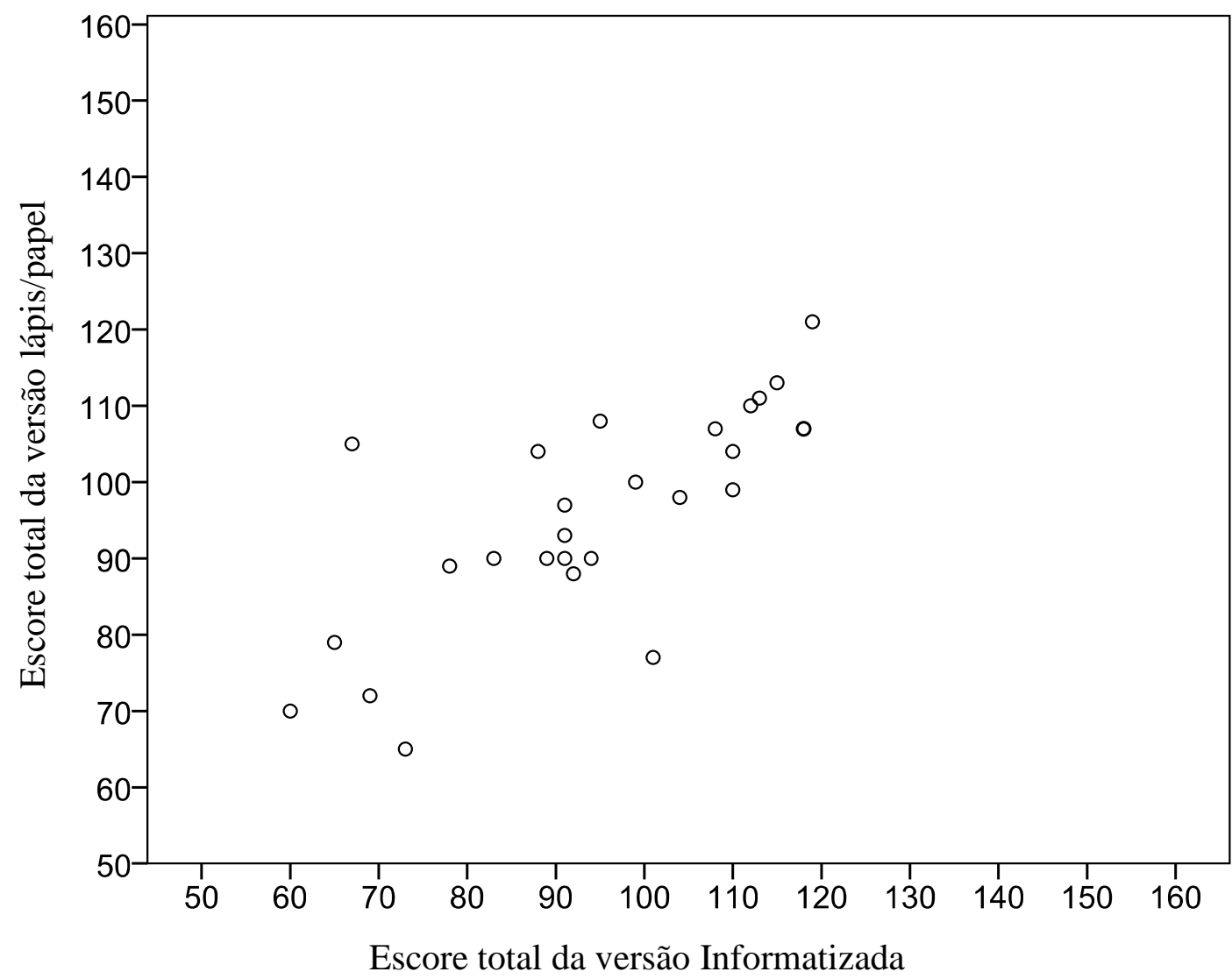

Figura 1. Diagrama de dispersão do escore total da versão lápis-papel e da versão informatizada

Tabela 2. Estatísticas descritivas do escore total na escala SAS Português $_{\text {por ordem de aplicação }}$

\begin{tabular}{|c|c|c|c|c|c|c|c|}
\hline \multirow[b]{2}{*}{ Ordem de aplicação } & \multirow[b]{2}{*}{$\mathrm{N}$} & \multicolumn{6}{|c|}{ Pontuação da escala SAS $_{\text {Português }}$} \\
\hline & & Média & $\begin{array}{l}\text { Desvio } \\
\text { padrão }\end{array}$ & $\begin{array}{l}\text { Correlação } \\
(r)\end{array}$ & $\begin{array}{l}\text { Significância de } \\
\text { correlação }(p)\end{array}$ & $\begin{array}{l}\mathrm{de} \\
\text { Student }\end{array}$ & $\begin{array}{l}\text { Significância de } \\
\text { diferença }(p)\end{array}$ \\
\hline $\begin{array}{l}\text { Lápis-pape/ } \\
\text { Informatizado }\end{array}$ & 11 & $\begin{array}{l}94,18 \\
92,27\end{array}$ & $\begin{array}{l}8,852 \\
14,051\end{array}$ & 0,925 & 0,000 & 0,937 & 0,371 \\
\hline $\begin{array}{l}\text { Informatizado/ } \\
\text { Lápis-papel }\end{array}$ & 15 & $\begin{array}{l}94,67 \\
96,07\end{array}$ & $\begin{array}{l}19,744 \\
17,462\end{array}$ & 0,711 & 0,003 & 0,379 & 0,710 \\
\hline
\end{tabular}

\section{Conclusão e Considerações finais}

Os resultados desta pesquisa revelaram evidências de validade da escala informatizada de atitudes em relação à Estatística eSAS Português por meio da análise correlacional entre as versões lápis-papel e eletrônica da escala SAS de atitudes ante a estatística. Assim, este é um instrumento nacional que pode ser disponibilizado para o uso de pesquisadores e profissionais dessa área de estudo.

Vale ressaltar que a construção de instrumentos na versão informatizada tem sido mais frequente em outros países que no Brasil. Segundo Andriola (2003), ainda é limitada a produção experimental de instrumentos nacionais informatizados, que é maior do que sua comercialização e, portanto, não disponível para o uso profissional. Quando considerado o tema Atitudes em relação à estatística, a afirmação anterior se torna ainda mais verdadeira, considerando que estudos que têm o objetivo de ampliar e incentivar as pesquisas na área da educação estatística surgiram em meados dos anos 70 e os instrumentos utilizados nessa época ainda se 
encontram em uso, não havendo mudanças quanto ao seu formato (lápis-papel para a versão informatizada), e a produção de novos instrumentos ainda é restrita nesta área (Bayer, Bittencourt, Rocha \& Echeveste, 2004).

O emprego das escalas de atitudes ante a estatística pode auxiliar professores que ministram a disciplina para reconhecerem e se atentarem aos comportamentos, aos aspectos afetivos e às atitudes dos alunos no processo de ensino-aprendizagem, para então propor estratégias que visem reduzir ou eliminar esses aspectos negativos dos alunos promovendo, dessa forma, o melhor desenvolvimento deste processo. Para isso, as escalas de atitudes podem ser aplicadas no início e no final do ano ou semestre letivo para verificar a eficácia e dinâmica da classe. As atitudes mais positivas facilitam o processo da aprendizagem, melhorando o desempenho acadêmico do aluno. De acordo com Gordon (1995) citado por Mendes (2003), as experiências, interesses e objetivos influenciam as percepções dos estudantes sobre a aprendizagem da estatística e, portanto, o ensino da mesma deve favorecer as atitudes positivas tanto no aprendizado quanto no uso prático. Já o uso da tecnologia, nesse processo, vem contribuir para facilitar o processo de avaliação e análise com maior rapidez.

Embora haja limitações quanto à produção de instrumentos informatizados, em especial instrumentos que avaliem as Atitudes diante da disciplina de estatística, ressalta-se que o estudo em questão possibilita a identificação de algumas das possíveis vantagens no uso de testes informatizados, como, por exemplo, a rapidez de aplicação, com duração de aproximadamente quinze minutos; redução dos gastos, em função da substituição do material anteriormente impresso pela versão virtual; maior confiabilidade nas respostas dadas aos itens via internet, uma vez que os dados não precisaram ser digitados por uma terceira pessoa; maior segurança garantida por senha e código de acesso exclusivo de cada participante, que recebe em seu e-mail pessoal as informações de acesso. Embora não corresponda aos objetivos deste trabalho, ressaltase ainda que o instrumento informatizado, caso o pesquisador desejar, pode ser disponibilizado na rede mundial de computadores (internet), o que ampliaria a diversidade da amostra em âmbito regional, nacional ou internacional para o estudo de um mesmo instrumento. Ainda, sobre as características do presente estudo, sugere-se a pertinência do método utilizado comparação entre grupos em intervalo de quinze dias entre as aplicações das versões do instrumento - em relação à não variação das atitudes no período de aplicação dos instrumentos (Silva e colaboradores,
2007).

Apesar de haver alguns estudos sobre o uso da tecnologia para a testagem psicológica, a literatura disponível é ainda restrita no que se refere à transição dos formatos e procedimentos adotados para informatização dos testes, o que dificultou a discussão de resultados. Assim, sugere-se a elaboração de mais pesquisas nacionais nesta área e com amostras maiores a fim de evidenciar resultados mais confiáveis, corroborando o estudo de Vendramini, Bueno, Silva e Lopes (2011).

A escala eSAS Português apresenta evidências de validade, porém sugere-se a realização de novos estudos com ela e outras de mesma natureza, com a finalidade de proporcionar aos profissionais mais ferramentas que os auxiliem em seu trabalho, permitindo, assim, que suas escolhas sejam mais adequadas.

\section{Referências}

Adánez, G. P. (1999). Procedimientos de construccion y analisis de tests psicometricos. Em S. M. Wechsler \& R. S. L. Guzzo (Orgs.). Avaliação psicológica: perspectiva internacion (pp. 57-100). São Paulo: Casa do Psicólogo.

Andriola, W. B. (2003). Uso de computadores na avaliação psicológica: estudo de sua influência sobre o desempenho individual em um teste de raciocínio numérico (RN). Interaçôes, 8(15), 105124.

Bayer, A., Bittencourt, H., Rocha, J. \& Echeveste, S. (2004). A estatística e sua bistória. Trabalho apresentado no XII Simpósio Sulbrasileiro de Ensino de Ciências. Canoas: Rio Grande do Sul, Brasil. Recuperado em 15/10/2010 de http://www.exatas.net/estatistica.htm.

Carmona, J. M. (2004). Una revisión de las evidencias de fiabilidad e validez de los cuestionarios de actitudes y ansiedad hacia la estadística. Statistics Education Research Journal, 3(1), 5-28.

Gal, I. \& Ginsburg, L. (1994). The role of beliefs and attitudes in learning statistics: towards an assessment framework. Journal of Statistics Education [On-line], 2(2). Disponível em http://www.amstat.org/publications/jse/v2n2/ga l.html.

Joly, M. C. R. A. (2004). Evidências de validade de uma escala de desempenho docente em informática educacional. Psico-USF, 9(2), 117-134.

Joly, M. C. R. A. \& Martins, R. X. (2005). Estudo de validade da Escala de Desempenho em 
Informática Educacional para professores. Revista Avaliação Psicológica, 4(2), 105-114.

Joly, M. C. R. A., Martins R. X., Abreu, M. C., Souza, P. R. R. \& Cozza H. F. P. (2004). Análise da produção científica em avaliação psicológica informatizada. Avaliação Psicológica, 3(2), 121-129.

Joly, M. C. R. A., Welter, G. M. R., Martins R. X., Marini, J., Montiel, J. M., Lopes, F. \& Carvalho, M. R. (2005). Sistema de avaliação para testes informatizados (SAPI): estudo preliminar. PSIC Revista de Psicologia da Vetor Editora, 6(2), 51-60.

Mendes, C. R. (2003). Uma análise sobre a atitude em relação à estatística, a confiabilidade e a importância atribuídas a essa ciência. Trabalho apresentado no GT19 - Educação Matemática da $26^{a}$ Reunião Anual da ANPED. Disponível em http://www.anped.org.br/reunioes/26/trabalhos /claydereginamendes.rtf.

Moriya, T. M., Gir, E. \& Hayashida, M. (1994). Escala de atitude frente à AIDS: uma análise psicométrica. Revista Latino-Americana de Enfermagem, 2(2), 37-53.

Noronha, A. P. P., Santos, A. A. A. \& Sisto, F. F. (2006). Facetas do fazer em avaliação psicológica. São Paulo: Vetor.

Noronha, A. P. P., Vendramini, C. M. M., Canguçu, C., Souza, C. V. R, Cobêro C., Paula, L. M., Franco, M. O., Lima O. M. P., Guerra, P. B. C. \& Filizatti, R. (2003). Propriedades psicométricas apresentadas em manuais de testes de inteligência. Psicologia em Estudo, 8(1), 93-99.

Olea, J., Ponsoda, V. \& Prietro, G. (1999). Tests informatizados: fundamentos $y$ aplicaciones. Madrid: Pirámide.

Pasquali, L. (2010). Instrumentação psicológica: fundamentos e práticas. Porto Alegre: Artmed.

Prado, O. Z. (2005). Softwares para psicologia: regulamentação, produção nacional e pesquisas em psicologia clínica. Boletim de Psicologia, 55(123), 189204.

Robert, D. M. \& Bildebark, E. W. (1980). Reliability and validity of a statistics attitudes survey. Educational and Psychological Measurement, 40, 235-
238.

Silva, C. B., Brito, M. R. F., Cazorla I. M. \& Vendramini, C. M. M. (2002). Atitudes em relação à estatística e à matemática. Psico-USF, 7(2), 219228.

Silva, M. C. R., Vendramini C. M. M. \& Dias, A. S. (2007). Atitudes de estudantes de Psicologia em relação à estatística. Trabalho apresentado no VIII Congresso Nacional de Psicologia Escolar e Educacional. São João del Rey, Minas Gerias, Brasil.

Vendramini, C. M. M. (2006). Contribuições da educação estatística para a educação matemática. Em M. R. F. de Brito (Org.). Solução de problemas e a matemática escolar (pp. 237-252). Campinas, SP: Alínea.

Vendramini, C. M. M. (2009). Avaliação de uma escala brasileira de atitudes em relação à estatística. Revista de Psicologia, Educação e Cultura, 13(1), 55-71.

Vendramini, C. M. M. (2010). Desenvolvimento e validação de uma escala de atitudes em relação à estatística. Relatório técnico não-publicado (CNPq 481177/2008-6).

Vendramini, C. M. M. \& Brito, M. R. F. (2001). Relações entre atitude, conceito e utilidade da estatística. Psicologia Escolar e Educacional, 5(1), 5963.

Vendramini, C. M. M., Bueno, J. M. P., Silva, F. C. M. \& Lopes, F. L. (2011). O modelo de créditos parciais na avaliação de uma escala informatizada de atitudes. Em M. C. A. R. Joly \& C. T. Reppold (Orgs.). Estudos de testes informatizados para a avaliação psicológica (pp. 277-300). São Paulo: Casa do Psicólogo.
Recebido em 01/06/2011

Reformulado em 07/18/2011

Aprovado em 01/11/2011 
Sobre as autoras:

Claudette Maria Medeiros Vendramini é graduada e mestre em Estatística e doutora em Educação pela Universidade Estadual de Campinas-UNICAMP. Professora e pesquisadora da graduação e Pós-Graduação Stricto Sensu em Psicologia da Universidade São Francisco - USF. Tem experiência na área de Psicologia, com ênfase em Construção e Validade de Testes, Escalas e Outras Medidas Psicológicas, atuando em: avaliação educacional; crenças, atitudes e ansiedade matemática e estatística; educação estatística; ensino superior; evidências de validade do ENADE para avaliação de cursos superiores; psicometria. Bolsista nível 1D, Produtividade em Pesquisa do CNPq. Consultora ad hoc do INEP/MEC de 2004 a 2007. Membro do diretório de pesquisa Laboratório de Avaliação Psicológica e Educacional do CNPq e vice-líder do grupo de Psicologia da Educação Matemática - UNICAMP.

Juliana Maximila de Paula Bueno é graduada em Psicologia pela Universidade São Francisco - USF, participou do Programa de Iniciação Científica (PIC/USF), com bolsa PIBIC/CNPq, sob a orientação da Prof ${ }^{a}$ Dra. Claudette Maria Mendes Vendramini. Atualmente é mestranda do Programa Pós-Graduação Stricto Sensu em Psicologia da Universidade São Francisco.

Evelyn Christina Peres Barrelin é graduada em Psicologia pela Universidade do Vale do Sapucaí - UNIVÁS, mestre em Psicologia Experimental: Análise do Comportamento pela Pontifícia Universidade Católica de São Paulo - PUC-SP. Possui especialização em Terapia por Contingências de Reforçamento pelo Instituto de Terapia por Contingências de Reforçamento - ITCR-Campinas, com aperfeiçoamento em Psicologia da Saúde pela Universidade Católica de Campinas - PUC-Campinas e em Formação em Terapia por Contingências de Reforçamento pelo Instituto de Terapia por Contingências de Reforçamento. Professora Auxiliar do Curso de Psicologia da Universidade São Francisco. 
